\title{
Long-term regional precipitation disparity in northwestern China and its driving forces
}

\author{
H. F. Lee, Q. Pei, D. D. Zhang, and K. P. K. Choi
}

Department of Geography and the International Centre of China Development Studies, University of Hong Kong, Hong Kong, SAR

Received: 13 June 2014 - Accepted: 20 July 2014 - Published: 4 August 2014

Correspondence to: H. F. Lee (harrylee@hku.hk)

Published by Copernicus Publications on behalf of the European Geosciences Union.

Long-term regional precipitation disparity in northwestern China

H. F. Lee et al.

\section{Title Page}

\section{4}

4

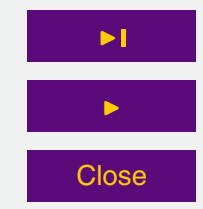

Back

Full Screen / Esc

Printer-friendly Version

Interactive Discussion 


\section{Abstract}

Subject to the unique physical setting of northwestern China (NW China), precipitation in the region is characterized by salient regional differences. Yet, the long-term regional precipitation disparity in NW China still remains insufficiently-explored. In the 5 present study, we base on historical documentation to reconstruct the precipitation indices of two macro regions in NW China between AD580-1979 to address the following issues: (1) determine the multi-decadal to centennial regional precipitation disparity in NW China, a topic which has not been systematically examined in previous paleo-climate/paleo-environment studies; and (2) find the major driving forces behind 10 it. Wavelet analysis, which is ideal for analyzing non-stationary systems, is applied. Our results show that there is significant regional discrepancy of precipitation change in NW China over extended period. Although there is significant association between the regional precipitation disparity in NW China and various modes of atmospheric circulation, the association is characterized by a regime shift during the transition from 15 the Medieval Warm Period to the Little Ice Age. Most importantly, the low-frequency cycle of the El Niño-Southern Oscillation is found to be the most prominent pacemaker of regional precipitation disparity in NW China at the multi-decadal to centennial timescales. Our findings help to demonstrate which atmospheric circulation is primarily responsible for the long-term regional precipitation disparity in NW China, which may have important implications for water resource management in NW China in the near future.

\section{Introduction}

Northwestern China (NW China) includes the autonomous regions of Xinjiang and Ningxia and the provinces of Sha'anxi, Gansu, and Qinghai. The total area of the region is 3.09 million $\mathrm{km}^{2}$, comprising approximately one-third of China's land area. Arid regions occupy a vast area in NW China, where the mean annual rainfall is less than

\section{CPD}

10, 3097-3125, 2014

\section{Long-term regional precipitation disparity in northwestern China}

H. F. Lee et al.

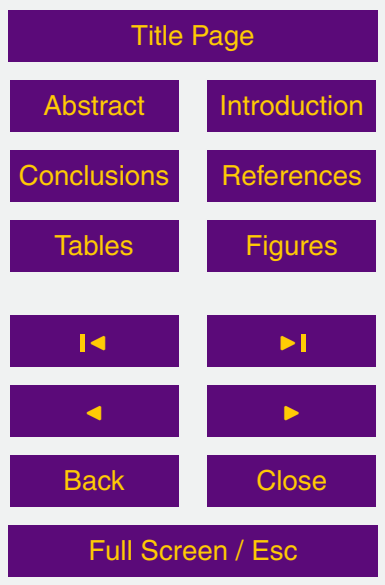

Printer-friendly Version

Interactive Discussion 
$250 \mathrm{~mm}$. Within the region, annual precipitation in the western plains is in the range of 50 to $150 \mathrm{~mm}$, and less than $25 \mathrm{~mm}$ in the Taklimakan Desert. Annual evaporation, however, is more than $1400 \mathrm{~mm}$ on average, and about 2000 to $3000 \mathrm{~mm}$ in the desert areas. Because of the arid climate, only a small portion of the total area in the re5 gion is used for farm production $\left(\sim 0.13\right.$ million $\left.\mathrm{km}^{2}\right)$. Irrigated farmlands are located primarily in Ningxia Plain, Hexi Corridor Region in Gansu and the northern oasis area of Xinjiang. In other parts of this region, most of the cultivated area is rain-fed, with scattered irrigated areas (Deng et al., 2005). Precipitation has been a limiting factor for the economy and society in NW China (Yuan, 1994). In terms of physical productivity 10 and socioeconomic capability to adapt, NW China is the region in China with the highest agricultural vulnerability (Lin, 1996). Scientific studies that examine the long-term (i.e., multi-decadal to centennial) dynamics of precipitation in NW China have received special attention in the last two decades, because the dynamics at these timescales are vital for predicting the future societal impacts brought by precipitation change.

One difficulty in understanding and predicting regional precipitation variability lies in the short instrumental precipitation records in NW China. Meteorological records only begin in the AD1950s. Fortunately, there are several high-resolution reconstructions based on historical documentary records (Tan et al., 2008; Yan et al., 1993), cave speleothems (Tan et al., 2011a; Zhang et al., 2008; Cai et al., 2010), and tree-ring chronologies (Li et al., 2006, 2007; Fang et al., 2009b, a, 2012; Yang et al., 2014; Sheppard et al., 2004) to address the long-term dynamics of precipitation/moisture change in NW China. The above studies help to unveil the complex climate dynamics in different parts of NW China over extended periods. At the same time, the associated reconstructions enable us to place recent climatic conditions in a long-term context of climate change and allow us to evaluate the sensitivity of recent climate changes to natural or anthropogenic forces. Nevertheless, the inherent limitation of those reconstructions is that they are based on proxy records from single localities. For example, cave speleothems and tree-ring chronologies are only available at specific sites. Given that the geographical distributions of proxies strongly affects the reconstructions

\section{CPD}

10, 3097-3125, 2014

\section{Long-term regional precipitation disparity in northwestern China}

H. F. Lee et al.
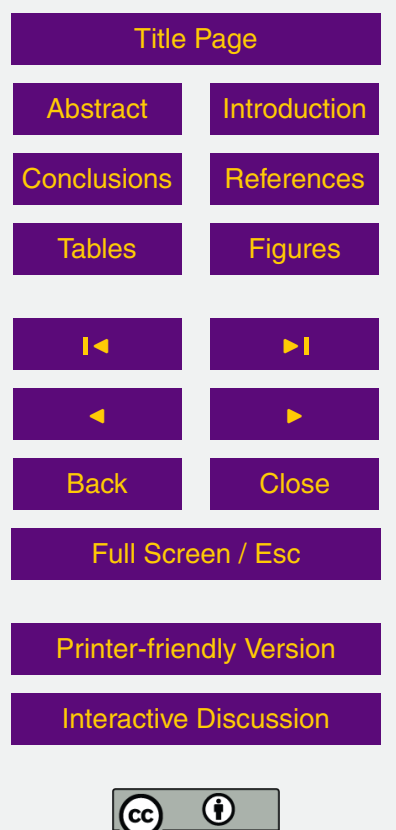
(Zhang et al., 2010; Timm and Ruprecht, 2004), the validity of those reconstructions' findings may be confined to specific places of NW China only. It is worth mentioning that NW China sits at the present-day northern limit of the Asian Summer Monsoon (ASM) (Fig. 1). The areas south and north of the ASM limit are characterized by differ5 ent climatic conditions (Chen et al., 2008, 2010). The hydrological balance and effective moisture of the region is controlled by the interactions of three planetary-scale atmospheric circulations: ASM, Winter Monsoon, and Westerlies (Zhao, 1986; Tan et al., 2008). Subject to this unique geographic setting, precipitation in NW China is characterized by salient regional differences. This inherent spatial heterogeneity makes it 10 impossible to apply generalizations about the precipitation regime of any single locality to other parts of NW China.

In the present study, we seek to: (1) discover the long-term (i.e., multi-decadal to centennial) regional precipitation disparity in NW China, a topic that has not been systematically examined in previous paleo-climate/paleo-environment studies, (2) find the 15 major driving forces behind it.

\section{Data and method}

\subsection{Reconstruction of paleo-precipitation}

In the present study, we base on historical documentation to reconstruct the paleoprecipitation of NW China. Generally speaking, Chinese historical documents are accurate in chronology and unambiguous in their description of dry/wet and warm/cold conditions (Zhang et al., 2010). Historical records can be an accurate source of data in locating disaster events in a long time span, particularly when the events are recorded on an annual basis (Chu et al., 2008). They represent a wide spectrum of climate variability, encompassing annual to centennial timescale evidence of past changes.

Yuan (1994) compiled and tabulated a detailed inventory of natural disasters for NW China, Disaster History of Northwestern China, spanning AD580-1979, which provides

\section{CPD}

10, 3097-3125, 2014

\section{Long-term regional precipitation disparity in northwestern China}

H. F. Lee et al.

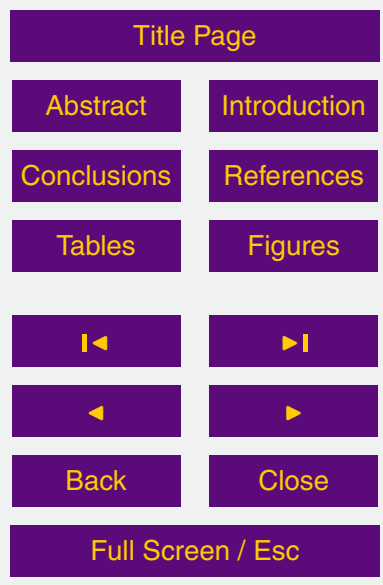

Printer-friendly Version

Interactive Discussion 
the required data (i.e., flood and drought disasters) for precipitation reconstruction. In his compilation, Yuan (1994) relied on a careful survey of 685 volumes of various official dynastic histories, local chronicles, and instrumental data from local meteorological stations to tabulate flood and drought disasters for two macro regions, namely 5 Gan-Ning-Qing Region (GNQR, including Gansu, Ningxia, and eastern Qinghai) and Sha'anxi. The two regions cover more the $50 \%$ of the inhabited area in NW China (Lin, 1996). Yuan's (1994) dataset is in printed copy, which is believed to be one of the most accurate and comprehensive historical flood and drought disaster datasets for NW China. We cross-checked his records with the original historical documents as 10 far as possible, and no errors are found. We have also applied the same dataset in our previous studies (see Lee and Zhang, 2010, 2011, 2012). Hence, it is employed to reconstruct the paleo-precipitation of NW China. Corresponding to Yuan's (1994) dataset, our study area is delimited to the GNQR and Sha'anxi (Fig. 1) and our study time span is delimited to AD580-1979.

15 Although historical climate records have accurate dates and clear climatic information, they are usually qualitative descriptions. They need to be parameterized prior to quantitative analysis. In reference to previous studies (Jiang et al., 2005; Tan et al., 2008), we employ Yuan's (1994) historical drought/flood records to reconstruct Precipitation Indices for the GNQR $\left(\mathrm{PI}_{\mathrm{GNQR}}\right)$ and Sha'anxi $\left(\mathrm{PI}_{\text {Sha'anxi }}\right)$, respectively (Fig. $2 \mathrm{a}$ and $b$ ). The PIs of the two regions are derived from the following formula:

$\mathrm{PI}=2(F-D) /(F+D)$

where $F$ and $D$ represent the decadal frequencies of flood and drought, respectively. The index is in decadal units. If the occurrence of flood and drought events is equal, 25

$\mathrm{PI}=0$ (also if no flood and drought events are measured); if the climate is wet or dry, $\mathrm{PI}$ is $>1$ or $<1$. To control the possible trend of historical documents in recording minor events in a later period, only those floods and droughts which affect $>10 \%$ of the total area of the GNQR/Sha'anxi in a year will be considered. The calculation of affected area is based on the following principle: each of the regions is broken down into

\section{CPD}

10, 3097-3125, 2014

\section{Long-term regional precipitation disparity in northwestern China}

H. F. Lee et al.

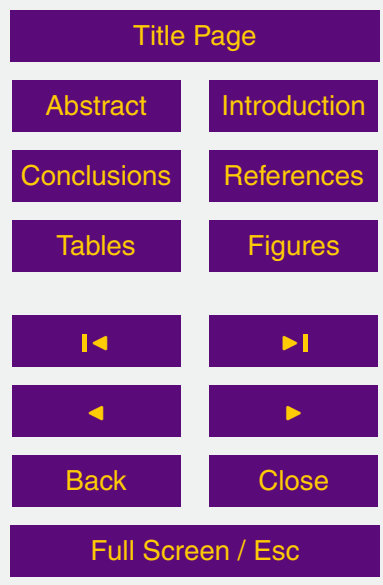

Printer-friendly Version

Interactive Discussion 
a number of geographic units, with spatial weighting assigned to each geographic unit according to its land area (see Tables S1 and S2 in Supplement for the spatial weightings employed). The flood/drought disaster of each region will be quantified on a yearly basis by summing up the spatial weightings of the affected regions. If flood/drought 5 affected only part of a geographic unit, half of the geographic unit's weighting would be applied. If a county in a geographic unit was in drought, one mark would also be given. This method has been employed in our previous studies (see Lee and Zhang, 2010, 2011, 2012). Usually, the resulting index values will be further converted to five grades according to some threshold values. However, this practice may sacrifice some 10 signals embedded in time series. Therefore, we skip this step when reconstructing the precipitation indices.

We also compare our $\mathrm{PI}_{\mathrm{GNQR}}$ and $\mathrm{PI}_{\text {Sha'anxi }}$ with Tan et al.'s (2011b) north central China decadal precipitation index to check whether they contain any significant dating errors. Tan et al.'s (2011b) index is synthesized by high-resolution precisely-dated 15 stalagmite records and historical document records. It is chosen as our reference timeseries because it overlaps with our entire study timespan and covers part of GNQR and part of Sha'anxi at the same time. As indicated by our statistical test results, no significant dating errors are found (see Robustness Test in Supplement). The full reconstructions of $\mathrm{PI}_{\mathrm{GNQR}}$ and $\mathrm{PI}_{\text {Sha'anxi }}$ are given in Table S3 in Supplement.

Geographically, the GNQR is influenced more by the Westerlies, while Sha'anxi is influenced more by Asian Summer Monsoon. The two regions are under different climatic regimes. $\mathrm{PI}_{\mathrm{GNQR}}$ and $\mathrm{PI}_{\text {Sha'anxi }}$ will be compared to spot the regional precipitation disparity in NW China. At the same time, in reference to Osborn and Briffa (2006), we employ the following formula to compose an index to quantify the regional precipitation

$$
\mathrm{RPD}=\mathrm{PI}_{\mathrm{GNQR}}-\mathrm{PI}_{\text {Sha'anxi }}
$$

\section{CPD}

10, 3097-3125, 2014

\section{Long-term regional precipitation disparity in northwestern China}

H. F. Lee et al.

\section{Title Page}

Abstract Introduction Conclusions References Tables Figures

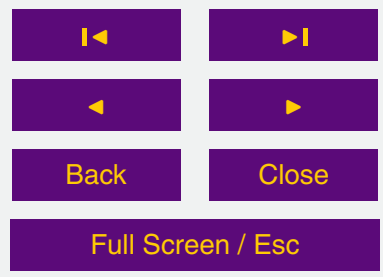

Printer-friendly Version

Interactive Discussion 


\subsection{Atmospheric circulation data}

Atmospheric circulations play an important role in modulating hydro-climatic changes in East Asia. Recent studies also demonstrate the effect of various atmospheric circulations in driving pluvial events in different localities of NW China (Lee and Zhang, 5 2011, 2010; Tan et al., 2008, 2011b; Li et al., 2006, 2007; Fang et al., 2009b, a, 2012; Cai et al., 2010). In this study, we take a step forward to investigate whether longterm regional precipitation disparity in NW China (if any) is also attributable to some major atmospheric circulations such as Asian Summer Monsoon (ASM), Artic Oscillation (AO), Pacific Decadal Oscillation (PDO), North Atlantic Oscillation (NAO), and El 10 Niño-Southern Oscillation (ENSO).

Research in the last decade has ushered in significant improvement in using multiproxy data to generate high-resolution reconstructions of large-scale atmospheric circulations over extended period. Our atmospheric circulation data are retrieved from the homepage of NOAA's National Climatic Data Centre (NCSC) (http://www.ncdc. noaa.gov/data-access/paleoclimatology-data/datasets/climate-reconstruction). NCSC is one of the largest online climatic information database systems, providing highly reliable paleo-climate reconstructions. To match with the PIs (cf. Sect. 2.1), those data will be transformed into decadal units prior to statistical analysis.

\subsection{Wavelet analysis}

20 For climatic systems, transient dynamics appear to be the rule rather than the exception in nature, either because climatic processes are influenced by exogenous trends or because complex endogenous dynamics pre-dominate. This makes it inappropriate to apply traditional techniques (which make the assumption that the statistical properties of the time series do not vary with time) to analyze non-stationary time series or their mutual dependencies. Wavelet analysis is a powerful tool that is already in use throughout science and engineering. By performing a local time-scale decomposition of the signal, wavelet analysis is especially relevant to the analysis of non-stationary sys-

\section{CPD}

10, 3097-3125, 2014

\section{Long-term regional precipitation disparity in northwestern China}

H. F. Lee et al.

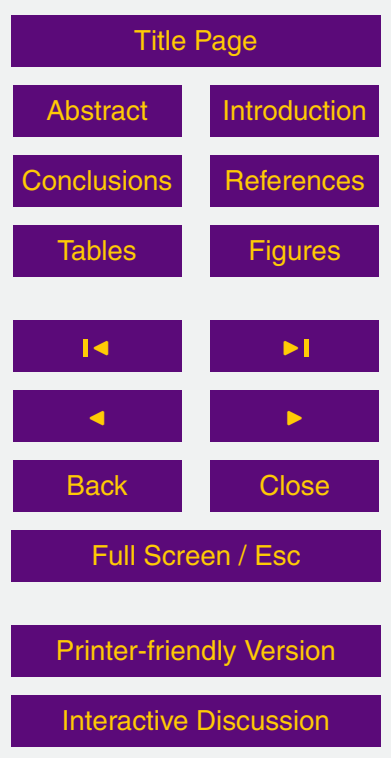

(i) 
tems (Torrence and Compo, 1998; Cazelles et al., 2007, 2008). The continuous wavelet transform decomposes the time series into both time and frequency components, the calculation of the wavelet power spectrum quantifies in the time-frequency domain the distribution of the variance of the time series (Grinsted et al., 2004; Cazelles et al., 5 2008). Through this approach, we can track how the different scales related to the periodic components of the signal change over time (Cazelles et al., 2008; Zhang et al., 2009). In this study, we employ wavelet coherency to present coherencies between two time series, in order to identify significant associations between two time series of specific frequency-time domain in complex systems (Grinsted et al., 2004; Cazelles et al., 10 2008). For our analyses, the Morlet wavelet is used to decompose signals, which is regarded as an efficient means of detecting and analyzing curves (Shyu and Sun, 2002), especially the variations in the periodicities of geophysical signals in a continuous way along time series (Rigozo et al., 2008). The significance level is set at $p<0.1$.

\section{Results}

\section{$15 \quad$ 3.1 Regional precipitation disparity in NW China}

To start with, we compare the long-term trends (five-order polynomial fit) of the $\mathrm{PI}_{\mathrm{GNQR}}$ and the $\mathrm{Pl}_{\text {Sha'anxi }}$. Both of them fluctuate in the same manner (Fig. 2a and b), revealing their synchrony at the multi-centennial to millennial timescales. However, there exists significant disparity between the two indices at the multi-decadal to centennial timescales, which is revealed by the RPD (Fig. 2c). The disparity is particularly apparent in AD600-900 and 1670-1979. We also compare the $\mathrm{PI}_{\mathrm{GNQR}}$ and the $\mathrm{PI}_{\text {Sha'anxi }}$ with the other precipitation/moisture reconstructions in other parts of NW China, namely Hai River and Xi'an region (Yan et al., 1993) and Longxi ${ }^{1}$ (Tan et al., 2008) (Fig. 2d and e). The two reconstructions are also derived from historical drought/flood records. We

${ }^{1}$ Longxi includes today's Lanzhou area, Dingxi area and the close-by Wushan County, Huining County, Gangu County, and Qin'an County.

\section{CPD}

10, 3097-3125, 2014

\section{Long-term regional precipitation disparity in northwestern China}

H. F. Lee et al.

\section{Title Page}

Abstract Introduction

Conclusions References

Tables Figures

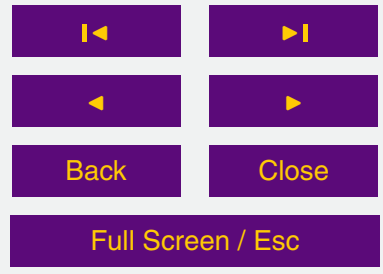

Printer-friendly Version

Interactive Discussion 
observe that their long-term trends basically match with the ones for the $\mathrm{PI}_{\mathrm{GNQR}}$ and the $\mathrm{PI}_{\text {Sha'anxi }}$ before AD1670. Yet, the five-order polynomial fits for the reconstructions of Hai River and Xi'an region and Longxi oppose each other since AD1670, concurring with the disparity between the $\mathrm{PI}_{\mathrm{GNQR}}$ and the $\mathrm{PI}_{\text {Sha'anxi }}$ in the same period (Fig. 2c).

5 We further compare the $\mathrm{PI}_{\mathrm{GNQR}}$ and the $\mathrm{PI}_{\text {Sha'anxi }}$ by examining their continuous wavelet power spectra and the average wavelet power spectra of their signals (Fig. 3a and b). We find statistically significant $\sim 30$ and $\sim 80$ year bands in both of the indices. But, $a \sim 250$ year band (which is nearly statistically significant) can only be perceived for the $\mathrm{PI}_{\text {Sha'anxi }}$. This marks the discrepancy of precipitation between the two regions. 10 For the precipitation/moisture of Hai River and Xi'an region and Longxi, they have a statistically significant $\sim 30$ year band (Fig. $3 c$ and d), which appears similar to the one found in the $\mathrm{PI}_{\text {GNQR }}$ and the $\mathrm{PI}_{\text {Sha'anxi }}$. However, there is a nearly statistically significant 100-150 year band in Hai River and Xi'an regions and Longxi, which differentiates them from the $\mathrm{PI}_{\mathrm{GNQR}}$ and the $\mathrm{PI}_{\text {Sha'anxi }}$. It is worth mentioning that the $\sim 150$ year band 15 for Hai River and Xi'an region is different from that for Longxi, a difference revealed by their continuous wavelet power spectra (see Appendix). Briefly, despite the presence of the common statistically significant periodicity (i.e., 30 year band), the marked difference of time and frequency domain of the above reconstructions should not be overlooked, which suggests that regional precipitation disparity is a prominent feature in

NW China. Furthermore, there is not any persistent mode of variability for all of the above reconstructions, which highlights the non-stationary nature of the precipitation in NW China.

We also examine the wavelet coherency between the $\mathrm{PI}_{\mathrm{GNQR}}$ and the $\mathrm{PI}_{\text {Sha'anxi }}$. Overlapped coherency analysis shows that there is significant common mode of oscillation between the $\mathrm{PI}_{\text {GNQR }}$ and the $\mathrm{PI}_{\text {Sha'anxi }}$ for a limited period of time only. For instance, there is $a \sim 150$ year band for the period AD580-900 and a 250 year band for the period AD1400-1900, while there is only weak association on high frequency bands (i.e., $<100$ year) in AD900-1400 (Fig. 3e). It is observed that the shifting of periodicity follows the alternation of major climatic episodes over the past two millennia, in which the

\section{CPD}

10, 3097-3125, 2014

\section{Long-term regional precipitation disparity in northwestern China}

H. F. Lee et al.

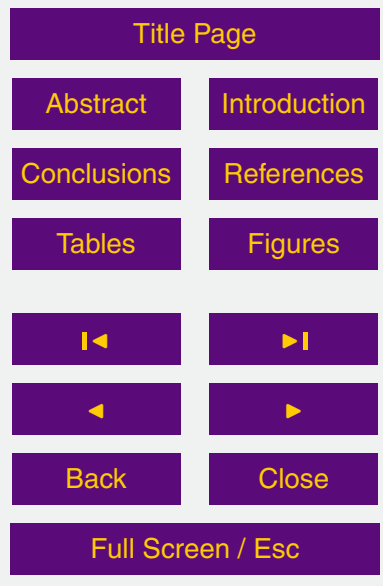

Printer-friendly Version

Interactive Discussion 
periodicity becomes weaker and shorter in warm Medieval Warm Period (MWP, circa the 9th to 11th centuries) and the Current Warm Period (CWP, circa late-19th century till now), while the periodicity becomes stronger and longer in cold pre-MWP and the Little Ice Age (LIA, circa the 14th to 19th centuries). We also compute the phases of 5 the two time series to obtain information about the possible delay in the coherence. We find that the two time series are in phase in the warm periods and out of phase in the cold periods. Generally, the inter-connection of precipitation change between the two regions is irregular and non-stationary throughout our study time span, which may be attributable to long-term hemispheric temperature change.

\subsection{Driving forces of the regional precipitation disparity in NW China}

\subsubsection{Asian Summer Monsoon}

The northern limit of ASM divides our study area into two parts (see Fig. 1). When ASM is strong, the monsoon precipitation in the area south of the monsoon limit (i.e., Sha'anxi and the southeastern part of the GNQR) increases, and vice versa (Tan et al., 15 2011b). This mechanism may be responsible for the disparity of precipitation between the GNQR and Sha'anxi at the multi-decadal to centennial timescales. Therefore, we examine the wavelet coherence between the RPD index and Zhang et al.'s (2008) ASM reconstruction, which is derived from the stalagmite in Wanxiang Cave in Gansu (Fig. 4a). Three significant periodicities are spotted: a 80-100 year band in AD58020

1300, a 150 year band in AD1600-1979, and a 250 year band in AD1300-1979. The above bands are horizontal, reflecting their constancy in the associated periods. It is worth noting that the regime shift from the shorter to the longer periodicity happens at around the 13th century - the turn between MWP and LIA.

It has been mentioned that the monsoon record reconstructed from the stalagmite 25 in Wanxiang Cave might not properly represent the vast area influenced by the ASM (Zhang et al., 2010), owing to the susceptibility of each individual site to the influence of site-specific conditions. Therefore, we compare Zhang et al.'s (2008) ASM recon-

\section{CPD}

10, 3097-3125, 2014

Long-term regional precipitation disparity in northwestern China

H. F. Lee et al.

\section{Title Page}

Abstract Introduction Conclusions References Tables Figures

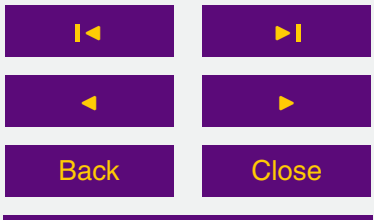
Full Screen / Esc

Printer-friendly Version

Interactive Discussion 
struction with the one derived from the stalagmite in Dandak Cave in east-central India spanned AD624-1562 (Berkelhammer et al., 2010). Their continuous wavelet power spectra are computed (Appendix). A strong 150 year band in the MWP is spotted for the two reconstructions. This shared periodicity of signals justifies the representative5 ness of Zhang et al.'s (2008) ASM reconstruction. At the same time, we also examine the wavelet coherence between the RPD index and the Berkelhammer et al.'s (2010) ASM reconstruction (Fig. 4b). We find a $~ 100$ year band for the full length of the time series, which matches with the 80-100 year band in AD580-1300 for Zhang et al.'s (2008) reconstruction (Fig. 4a). At the same time, the similarity of wavelet coherence 10 between Fig. 4a and b further substantiates the effect of ASM upon the inter-regional precipitation variability in NW China.

\subsubsection{Other atmospheric circulations}

The unique geographic setting of NW China implies that the regional precipitation variability there can be affected by multiple atmospheric circulations simultaneously 15 (Fig. 1). Although the coherence between ASM and regional precipitation disparity in NW China has been shown in the previous section, we need to test whether the regional precipitation disparity in NW China is also attributable to other atmospheric circulations.

We compare our RPD index with winter AO index reconstructed by Chu et al. $(2008)^{2}$. 20 There is a significant horizontal $~ 100$ year band in AD900-1400 and a $\sim 300$ year band in AD1000-1300 (Fig. 5a). It is observed that the above periodicities of signals appear in MWP and then disappear in LIA. We also compare the RPD index with the PDO index reconstructed by MacDonald and Case $(2005)^{3}$. Despite the scattering periodicities

\footnotetext{
${ }^{2}$ The index is developed from historical snow anomaly events in Eastern China $\left(25-46^{\circ} \mathrm{N}\right.$, $\left.100-130^{\circ} \mathrm{E}\right)$ spanned AD1-1899. The variation of positive/negative abnormal snow events represents an $\mathrm{AO}$-like atmospheric variability.

${ }^{3}$ PDO is defined as the time coefficient of the first empirical orthogonal function component of multi-decadal variability in sea surface temperature anomalies in the extra-tropical North Pa-

\section{CPD}

10, 3097-3125, 2014

\section{Long-term regional precipitation disparity in northwestern China}

H. F. Lee et al.

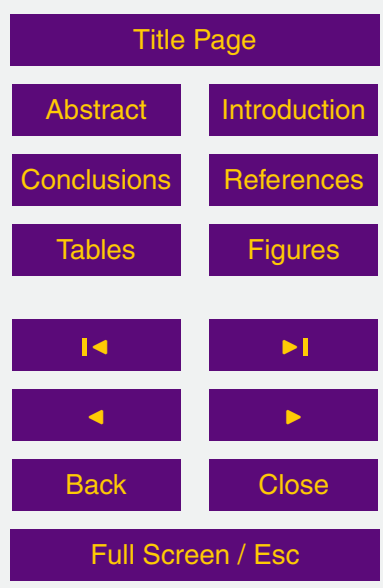

Printer-friendly Version

Interactive Discussion 
of signals, two significant continuous signals can be found: a 150-200 year band in AD1650-1900 and a 250 year band in AD1400-1550 (Fig. 5b). Seemingly, their periodicities of signals become stronger and longer in LIA.

Then, we compare the RPD index with the winter NAO index reconstructed by Trouet 5 et al. (2009) $)^{4}$. There are two significantly strong periodicities of coherence: $a \sim 150-$ 200 year band starting from AD1450 and a 250 year band starting from AD1350, both of which run till the end of the time series. Long periodicities of coherence have appeared since LIA, which is similar to the coherence between the RPD index and ASM (Fig. 4a) and that between the RPD index and PDO (Fig. 5c). Finally, we compare the 10 RPD index with the latest ENSO index reconstructed by Li et al. $(2013)^{5}$. We obtain a very thick $\sim 220-250$ year band for virtually the full length of the time series (Fig. 5d), representing a very strong association between the regional precipitation disparity in NW China and the low-frequency oscillation of tropical climate. In addition, their oscillations are coherent in 120-150 year band in AD1450-1550 and 1800-1900.

cific. Positive phases of the PDO are typified by warm sea surface temperatures in the northeastern Pacific. The index is developed from tree-ring chronologies from California and Alberta spanned AD993-1996. Those two sites lie at the opposite ends of the PDO precipitation dipole.

${ }^{4} \mathrm{NAO}$ is a climatic phenomenon in the North Atlantic Ocean of fluctuations in the difference of atmospheric pressure at sea level between the Icelandic Low and Azores High. The increased pressure difference between the Azores High and Icelandic Low during positive NAO phase results in enhanced zonal flow. The NAO index is defined as the difference of the aridity threshold proxies between Scotland and Morocco spanned AD1049-1995. These proxy records are located centrally in the opposing poles of NAO.

${ }^{5}$ ENSO refers to variations in the sea surface temperature (SST) of the tropical eastern Pacific Ocean and in air surface pressure in the tropical western Pacific. The two variations are coupled: the warm oceanic phase, El Niño, accompanies high air surface pressure in the western Pacific, while the cold phase, La Niña, accompanies low air surface pressure in the western Pacific. The winter Niño 3.4 index reconstruction is derived from tree-ring chronologies from Asia, New Zealand, and North and South America spanned AD1301-2005.

CPD

10, 3097-3125, 2014

\section{Long-term regional precipitation disparity in northwestern China}

H. F. Lee et al.

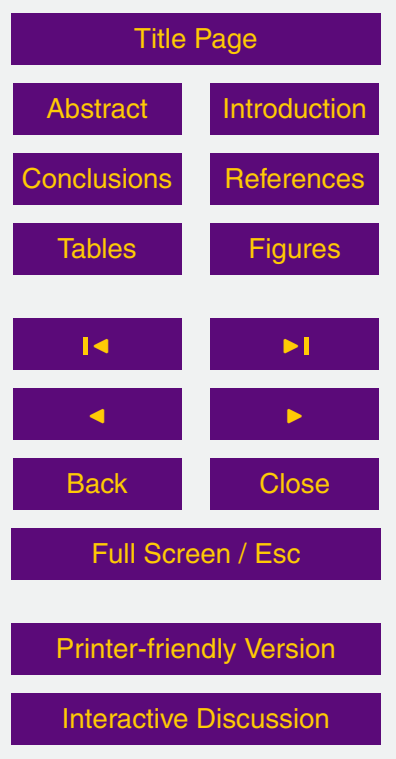


First, there is a discrepancy of precipitation change between the two regions in NW China (i.e., GNQR and Sha'anxi) in AD580-1979. Also, the inter-connection of precipitation change between the two regions is irregular and non-stationary, which may be attributable to long-term hemispheric temperature change. This highlights the spatial 5 heterogeneity of hydro-climatic change in NW China.

Second, there is significant association between the regional precipitation disparity in NW China (represented by the RPD index) and various modes of atmospheric circulations such as ASM, AO, PDO, NAO, and ENSO. However, the association is characterized by a regime shift during the transition period from MWP to LIA, in which 10 the periodicities of coherence between the RPD index and AO disappear, while the periodicities of coherence between the RPD index and other modes of atmospheric circulations (including ASM, PDO, and NAO) becomes longer. Their similar timing of the regime shift also echoes with the shifting of coherence periodicities and the switching of phase difference between the $\mathrm{PI}_{\mathrm{GNQR}}$ and the $\mathrm{PI}_{\text {Sha'anxi }}$ (cf. Sect. 3.1). On the 5 other hand, it also reveals the coupling among AO, PDO, and NAO as mentioned by Chu et al. (2008). As the first data point of Li et al.'s (2013) ENSO reconstruction starts in AD1301, we cannot show whether the regime shift also applies to the coherence between the RPD index and ENSO.

Third, although various atmospheric circulations are found to be correlated with the 20 inter-regional precipitation variability in NW China, the low-frequency cycle of ENSO is found to be the most prominent pacemaker of regional precipitation disparity in NW China at the multi-decadal to centennial timescales, which is also the first-ever piece of empirical evidence about their long-term relationship.

\section{Discussion}

Our reconstruction quantitatively extends the precipitation history of the GNQR and Sha'anxi back to AD580, providing a longer record to evaluate inter-regional moisture variability. Based on meteorological records, previous studies have classified western

\section{CPD}

10, 3097-3125, 2014

\section{Long-term regional precipitation disparity in northwestern China}

H. F. Lee et al.

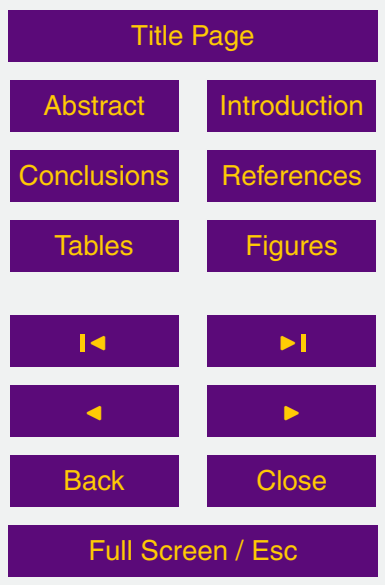

Printer-friendly Version

Interactive Discussion 
and eastern NW China as two different climatic regions (Shi et al., 2007; Qian and Qin, 2008). Our results show that there is significant precipitation disparity between the GNQR and Sha'anxi over extended period. In addition, the inter-connection of precipitation change between the two macro regions is weak and non-stationary. It is worth 5 mentioning that the two regions are located in the eastern part of NW China. Given the above findings, it may be necessary to further divide eastern NW China into two different climatic sub-regions.

The regime shifts for the coherence between $\mathrm{PI}_{G N Q R}$ and $\mathrm{PI}_{\text {Sha'anxi }}$ and between RPD index and various modes of atmospheric circulations reveals that long-term hemi10 spheric temperature change may be an imperative factor in modulating the connection between atmospheric circulations and the regional precipitation disparity in NW China at multi-decadal to centennial timescales. Hemispheric temperature affects the hydroclimate in NW China through the influence on the strength and the relative positions of ASM and Westerlies. Since oceanic and terrestrial heat capacity is different, when tem15 perature increases, the temperature of land increases quickly. The Tibetan Plateau further magnifies the thermal contrast between the Asian continent and the North Pacific. As a result, the lower-troposphere low-pressure system over eastern Asia strengthens, and the western Pacific sub-tropical high strengthens with its location shifting northward. In consequence, the ASM is strengthened and the Winter Monsoon is weakened, which causes the north edge of ASM to shift northward. At the same time, the increase of temperature forces the Westerlies to move northward and hence, ASM moves northward into the northwest interior and brings rainfall there. In contrast, when temperature decreases, the temperature of land decreases quickly, the Winter Monsoon is strengthened, ASM is weakened, and the north edge of ASM and Westerlies move southward synchronously, causing a decrease in the precipitation of NW China (Tan et al., 2011b, 2008). The effect of other atmospheric circulations upon the hydro-climate in NW China is also contingent upon the relative strength of ASM and Westerlies (Lee and Zhang, 2010, 2011; Yu et al., 2006). This amplifies the hydro-climatic influence of long-term hemispheric temperature fluctuation in NW China.

\section{CPD}

10, 3097-3125, 2014

\section{Long-term regional precipitation disparity in northwestern China}

H. F. Lee et al.

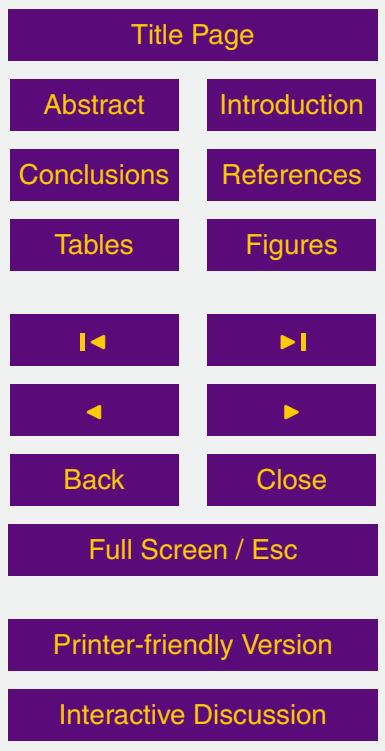


The long-term hydro-climatic influence of various atmospheric circulations upon different localities of NW China has been mentioned in previous paleo-climate studies (Lee and Zhang, 2011, 2010; Tan et al., 2008, 2011b; Li et al., 2006, 2007; Fang et al., 2009b, a, 2012; Cai et al., 2010). Yet, those studies cannot definitely answer which 5 atmospheric circulation is the most influential force in driving the regional precipitation disparity in NW China. Via systematic comparison, our results show that out of various atmospheric circulations, ENSO is the most prominent pacemaker of inter-regional precipitation disparity in NW China on the multi-decadal to centennial timescales. Although recent paleo-climate studies also highlight the tele-connection between ENSO activi10 ties and precipitation anomalies at individual sites in NW China on the inter-annual to decadal timescales (Li et al., 2007; Fang et al., 2009b, a, 2012; Li et al., 2006), we further show that ENSO can drive the regional precipitation disparity in NW China on the multi-decadal to centennial timescales. This further substantiates that the teleconnection is a consistent feature inherent to the climatic regime in NW China. The 5 tele-connection can be traced back at least to the early 14th century.

It is worth mentioning that although ENSO events occur at a frequency of 2-10 years, the QN chronology (Quinn and Neal, 1992) spanned AD1525-1987 reveals that El Niño phenomena had occurred throughout the Spanish colonization in Latin America with low variation frequency. In addition, multi-decadal to centennial association between El Niño and the net accumulation of ice at Guliya ice core in the Tibetan Plateau was also observed (Yang et al., 2000). Furthermore, it is proposed that the millennial-scale Holocene climate variability in NW China is linked to ENSO dynamics (Yu et al., 2006). Hence, the tele-connection between ENSO activities and precipitation change in NW China may not be only valid on the inter-annual to decadal timescales.

Concerning the possible mechanism linking ENSO and precipitation anomalies in NW China, Wang and Li (1990) note that when sea surface temperature in the equatorial eastern Pacific becomes warmer during El Niño years, the meridional temperature gradient will become larger, thus implying a stronger Hadley cell. A stronger Hadley circulation will induce a stronger intensity of the western Pacific sub-tropical high, which

\section{CPD}

10, 3097-3125, 2014

\section{Long-term regional precipitation disparity in northwestern China}

H. F. Lee et al.

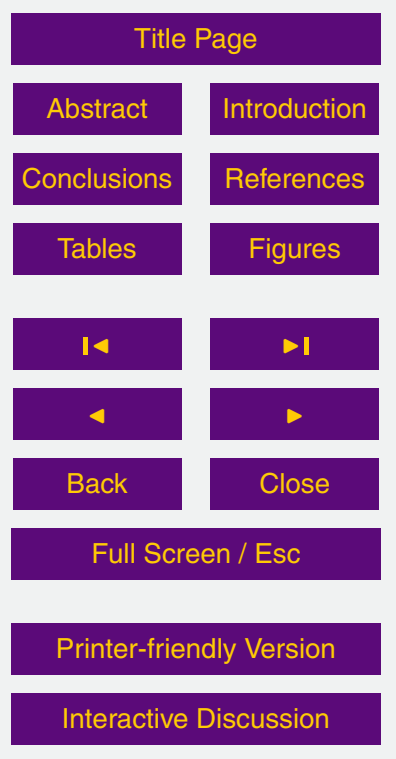


together with a westward shift of the location of the sub-tropical high can lead to a decrease in the extent of the northern latitude of ASM and result in a decrease of the precipitation in the semi-arid region of northern China. The effect will be more apparent in the southern part of the semi-arid region because it is subject more to the influence 5 of ASM than the northern part, which is also revealed by other related studies based on instrumental records (Xu et al., 2007; Su and Wang, 2007; Li et al., 2000). The above mechanism may explain the regional precipitation disparity of our study area. However, as Wang and Li's (1990) study is based on instrumental records, the above mechanism can only be taken as valid on the inter-annual timescale over the past few 10 decades. On longer timescales and over extended periods, there could be a regime shift for the coupling of ASM and ENSO and hence, a different mechanism responsible for the tele-connection between ENSO and inter-regional precipitation variability in NW China. The present study may provide a starting point for further investigation.

Finally, a strong 80-100 year band appears in the coherence between the RPD 15 index and various modes of atmospheric circulation (ASM, PDO, NAO, and ENSO) in the 20th century ${ }^{6}$ (Figs. $4 a$ and $5 b-d$ ). The twentieth century is characterized by rising temperature. The appearance of $\sim 80-100$ year periodicity may imply a regime shift of the coherence for the transition from LIA to CWP, just like the one during the transition from MWP to LIA. However, as the year band is below the cone of influence ${ }^{7}$, this should be interpreted with caution.

\footnotetext{
${ }^{6}$ As the last data point of Chu et al.'s (2008) winter AO reconstruction ends in AD1899, we cannot tell whether the same phenomenon applies to the coherence between the RPD index and $\mathrm{AO}$.

${ }^{7}$ As wavelet gets closer to the edge to time series, part of it exceeds the edge and thus the values of the wavelet transform are affected by the zeros introduced creating the boundary effect. Further, the affected region increases in extent as the scale of the wavelet increases. This zone where edge effects are present is called the "cone of influence" (see Torrence and Campo, 1998).
}

\section{CPD}

10, 3097-3125, 2014

\section{Long-term regional precipitation disparity in northwestern China}

H. F. Lee et al.

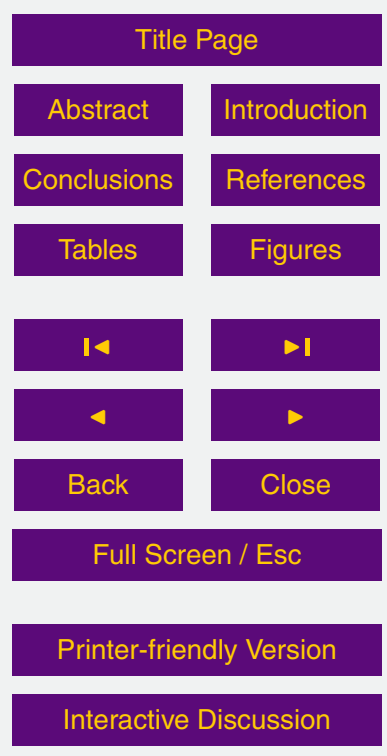




\section{Conclusions}

Since the AD1980s, average global temperature has continued to rise. The warmth is unprecedented over the past two millennia (Mann and Jones, 2003; Moberg et al., 2005), resulting in a more vigorous hydrological cycle (Su and Wang, 2007). Owing to 5 the interplay of the East Asian Summer Monsoon with the Westerlies at the northern boundary of the ASM limit, variations in the aridity threshold regime triggered by atmospheric circulation changes will be more pronounced in NW China than in other monsoon regions (Lee and Zhang, 2010). The spatial heterogeneity of climatic regimes in NW China in recent decades should be thoroughly investigated (e.g., Shi et al., 2007).

In the present study, we apply wavelet analysis to examine the long-term regional precipitation disparity in NW China in AD580-1979 and examine the major driving forces behind it. Our method is notably free from the assumption of stationarity, helping us to interpret multi-scale, non-stationary time-series data and reveal features we could not see otherwise. This is critically important in examining how gradual change 15 is forced by exogenous variables (Cazelles et al., 2008, 2007). We make a pioneering effort to examine quantitatively, and also present fine-grained picture, about the longterm regional precipitation disparity in NW China. Admittedly, our results are based on only two macro regions in NW China (i.e., GNQR and Sha'anxi). It is necessary for us to further expand the spatial coverage of our historical datasets to investigate the regional precipitation disparity across the entire NW China over an extended timespan. These efforts may help us to better understand problems such as the differential trends of hydro-climatic changes in the eastern and western parts of NW China since the AD1980s (Li et al., 2007; Shi et al., 2007). Further, the associated findings may have important implications for water resource management in NW China in the near future.

25 The Supplement related to this article is available online at doi:10.5194/cpd-10-3097-2014-supplement.

\section{CPD}

10, 3097-3125, 2014

Long-term regiona precipitation disparity in northwestern China

H. F. Lee et al.

\section{Title Page}

Abstract Introduction Conclusions References Tables Figures

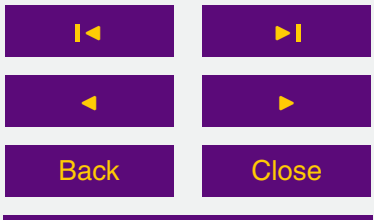
Full Screen / Esc

Printer-friendly Version

Interactive Discussion 
Acknowledgements. We thank J. B. Li for helpful discussions on the hydro-climatic influence of various atmospheric circulations on NW China. This research was supported by the Hui Oi-Chow Trust Fund (201205172003 and 201302172003), HKU Seed Funding Programme for Basic Research (201109159014), Research Grants Council of The Government of the 5 Hong Kong Special Administrative Region of the People's Republic of China (HKU758712H and HKU745113H), and the International Team of Innovation for the project entitled "Climate, Hydrology, Ecological Process, and Sustainable Use of Water Resources in Pan Hexi Region." Last but not least, a special thanks to Victor Brovkin for his valuable comments on the manuscript.

\section{References}

Berkelhammer, M., Sinha, A., Mudelsee, M., Cheng, H., Edwards, R. L., and Cannariato, K.: Persistent multidecadal power of the Indian Summer Monsoon, Earth Planet. Sc. Lett., 290, 166-172, 2010.

Cai, Y., Tan, L., Cheng, H., An, Z., Edwards, R. L., Kelly, M. J., Kong, X., and Wang, X.: The variation of summer monsoon precipitation in central China since the last deglaciation, Earth Planet. Sc. Lett., 291, 21-31, 2010.

Cazelles, B., Chavez, M., de Magny, G. C., Guégan, J. F., and Hales, S.: Time-dependent spectral analysis of epidemiological time-series with wavelets, J. R. Soc. Interface, 4, 625636, 2007.

Cazelles, B., Chavez, M., Berteaux, D., Ménard, F., Vik, J. O., Jenouvrier, S., and Stenseth, N. C.: Wavelet analysis of ecological time series, Oecologia, 156, 287-304, 2008.

Chen, F., Yu, Z., Yang, M., Ito, E., Wang, S., Madsen, D. B., Huang, X., Zhao, Y., Sato, T., Birks, H. J. B., Boomer, I., Chen, J., An, C., and Wuennemann, B.: Holocene moisture evolution in arid central Asia and its out-of-phase relationship with Asian monsoon history, Quaternary Sci. Rev., 27, 351-364, 2008.

Chen, F., Chen, J., Holmes, J., Boomer, I., Austin, P., Gates, J. B., Wang, N., Brooks, S. J., and Zhang, J.: Moisture changes over the last millennium in arid central Asia: a review, synthesis and comparison with monsoon region, Quaternary Sci. Rev., 29, 1055-1068, 2010.

\section{CPD}

10, 3097-3125, 2014

\section{Long-term regional precipitation disparity in northwestern China}

H. F. Lee et al.

\section{Title Page}

Abstract Introduction Conclusions References Tables Figures

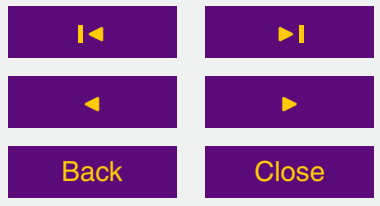

Full Screen / Esc

Printer-friendly Version

Interactive Discussion 
Chu, G., Sun, Q., Wang, X., and Sun, J.: Snow anomaly events from historical documents in eastern China during the past two millennia and implication for low-frequency variability of AO/NAO and PDO, Geophys. Res. Lett., 35, L14806, doi:10.1029/2008GL034475, 2008.

Deng, X., Luo, Y., Dong, S., and Yang, X.: Impact of resources and technology on farm production in northwestern China, Agr. Syst., 84, 155-169, 2005.

Fang, K., Gou, X., Chen, F., Li, J., D'Arrigo, R., Cook, E., Yang, T., and Davi, N.: Reconstructed droughts for the southeastern Tibetan Plateau over the past 568 years and its linkages to the Pacific and Atlantic Ocean climate variability, Clim. Dynam., 35, 577-585, 2009a.

Fang, K., Gou, X., Chen, F., Yang, M., Li, J., He, M., Zhang, Y., Tian, Q., and Peng, J.: Drought variations in the eastern part of northwest China over the past two centuries: evidence from tree rings, Clim. Res., 38, 129-135, 2009b.

Fang, K., Gou, X., Chen, F., Liu, C., Davi, N., Li, J., Zhao, Z., and Li, Y.: Tree-ring based reconstruction of drought variability (1615-2009) in the Kongtong Mountain area, northern China, Global Planet. Change, 80-81, 190-197, 2012.

Grinsted, A., Moore, J. C., and Jevrejeva, S.: Application of the cross wavelet transform and wavelet coherence to geophysical time series, Nonlin. Processes Geophys., 11, 561-566, doi:10.5194/npg-11-561-2004, 2004.

Jiang, T., Zhang, Q., Blender, R., and Fraedrich, K.: Yangtze Delta floods and droughts of the last millennium: abrupt changes and long term memory, Theor. Appl. Climatol., 82, 131-141, 2005.

Lee, H. F. and Zhang, D. D.: Natural disasters in northwestern China, AD 1270-1949, Clim. Res., 41, 245-257, 2010.

Lee, H. F. and Zhang, D. D.: Relationship between NAO and drought disasters in northwestern China in the last millennium, J. Arid Environ., 75, 1114-1120, 2011.

Lee, H. F. and Zhang, D. D.: Temperature change and natural disasters in northwestern China, Asian Geographer, 29, 89-108, 2012.

$\mathrm{Li}$, J., Gou, X., Cook, E. R., and Chen, F.: Tree-ring based drought reconstruction for the central Tien Shan area in northwest China, Geophys. Res. Lett., 33, L07715, doi:10.1029/2006GL025803, 2006.

30 Li, J., Chen, F., Cook, E. R., Gou, X., and Zhang, Y.: Drought reconstruction for north central China from tree rings: the value of the Palmer drought severity index, Int. J. Climatol., 27, 903-909, 2007.

\section{CPD}

10, 3097-3125, 2014

\section{Long-term regional precipitation disparity in northwestern China}

H. F. Lee et al.

\section{Title Page}

Abstract Introduction

Conclusions References

Tables Figures

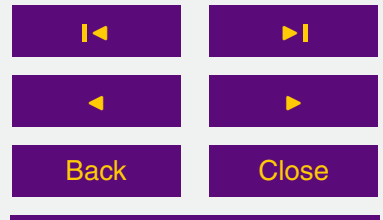

Full Screen / Esc

Printer-friendly Version

Interactive Discussion 
Li, J., Xie, S. P., Cook, E. R., Morales, M., Christie, D. A., Johnson, N. C., Chen, F., D'Arrigo, R., Fowler, A. M., Gou, X., and Fang, K.: El Niño modulations over the past seven centuries, Nature Climate Change, 3, 822-826, 2013.

$\mathrm{Li}, \mathrm{Y}$., Li, D., Zhao, Q., and Feng, J.: Effect of ENSO on the autumn rainfall anomaly in northwest China, Clim. Environ. Res., 5, 205-213, 2000.

Tan, L., Cai, Y., Yi, L., An, Z., and Ai, L.: Precipitation variations of Longxi, northeast margin of Tibetan Plateau since AD 960 and their relationship with solar activity, Clim. Past, 4, 19-28, doi:10.5194/cp-4-19-2008, 2008.

Lin, E.: Agricultural vulnerability and adaptation to global warming in China, Water Air Soil Poll., 92, 63-73, 1996.

MacDonald, G. M. and Case, R. A.: Variations in the Pacific decadal oscillation over the past millennium, Geophys. Res. Lett., 32, 1-4, 2005.

Mann, M. E. and Jones, P. D.: Global surface temperatures over the past two millennia, Geophys. Res. Lett., 30, 1820, doi:10.1029/2003GL017814, 2003.

Moberg, A., Sonechkin, D. M., Holmgren, K., Datsenko, N. M., and Karlén, W.: Highly variable Northern Hemisphere temperatures reconstructed from low- and high-resolution proxy data, Nature, 433, 613-617, 2005.

Osborn, T. and Briffa, K. R.: The spatial extent of 20th-century warmth in the context of the past 1200 years, Science, 311, 841-844, 2006.

20 Quinn, W. H. and Neal, V. T.: The historical record of El Niño events, in: Climate since 1500AD, edited by: Bradley, R. S. and Jones, P. D., Routledge, London, 623-648, 1992.

Rigozo, N. R., da Silva, H. E., Nordemann, D. J. R., Echer, E., de Souza Echer, M. P., and Prestes, A.: The Medieval and Modern Maximum solar activity imprints in tree ring data from Chile and stable isotope records from Antarctica and Peru, J. Atmos. Sol.-Terr. Phy., 70, 1012-1024, 2008.

Sheppard, P. R., Tarasov, P. E., Graumlich, L. J., Heussner, K. U., Wagner, M., Osterle, H., and Thompson, L. G.: Annual precipitation since $515 \mathrm{BC}$ reconstructed from living and fossil juniper growth of northeastern Qinghai Province, China, Clim. Dynam., 23, 869-881, 2004.

Shi, Y., Shen, Y., Kang, E., Li, D., Ding, Y., Zhang, G., and Hu, R.: Recent and future climate change in northwest China, Climatic Change, 80, 379-393, 2007.

Shyu, H. C. and Sun, Y. S.: Construction of a Morlet wavelet power spectrum, Multidim. Syst. Sign. P., 13, 101-111, 2002.

\section{CPD}

10, 3097-3125, 2014

\section{Long-term regional precipitation disparity in northwestern China}

H. F. Lee et al.

\section{Title Page}

Abstract Introduction

Conclusions References

Tables

Figures

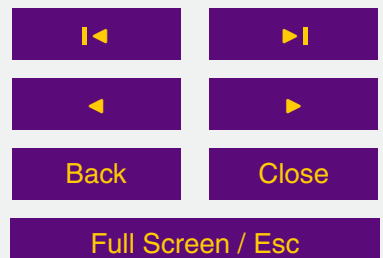

Printer-friendly Version

Interactive Discussion 
$\mathrm{Su}, \mathrm{M}$. and Wang, H.: Relationship and its instability of ENSO - Chinese variations in droughts and wet spells, Sci. China Ser. D, 50, 145-152, 2007.

Tan, L., Cai, Y., An, Z., Edwards, R. L., Cheng, H., Shen, C. C., and Zhang, H.: Centennialto decadal-scale monsoon precipitation variability in the semi-humid region, northern China

5 during the last 1860 years: records from stalagmites in Huangye Cave, Holocene, 21, 287296, 2011a.

Tan, L., Cai, Y., An, Z., Yi, L., Zhang, H., and Qin, S.: Climate patterns in north central China during the last $1800 \mathrm{yr}$ and their possible driving force, Clim. Past, 7, 685-692, doi:10.5194/cp7-685-2011, 2011b.

10 Timm, O. and Ruprecht, E.: Scale-dependent reconstruction of the NAO index, J. Climate, 17, 2157-2169, 2004.

Torrence, C. and Compo, G. P.: A practical guide to wavelet analysis, B. Am. Meteorol. Soc., 79, 61-78, 1998.

Trouet, V., Esper, J., Graham, N. E., Baker, A., Scourse, J. D., and Frank, D. C.: Persistent 15 positive North Atlantic Oscillation mode dominated the Medieval climate anomaly, Science, 324, 78-80, 2009.

Wang, W. C. and Li, K.: Precipitation fluctuation over semiarid region in northern China and the relationship with EI Niño/Southern Oscillation, J. Climate, 3, 769-783, 1990.

Xu, Z. X., Li, J. Y., Takeuchi, K., and Ishidaira, H.: Long-term trend of precipitation in China and

20 its association with the El Niño-southern oscillation, Hydrol. Process., 21, 61-71, 2007.

Yan, Z., Li, Z., and Wang, X.: An analysis of decade-to-century-scale climatic jumps in history, Scientia Atmospherica Sinica, 17, 663-672, 1993.

Yang, B., Qin, C., Wang, J., He, M., Melvin, T. M., Osborn, T. J., and Briffa, K. R.: A 3500-year tree-ring record of annual precipitation on the northeastern Tibetan Plateau, P. Natl. Acad. Sci. USA, 111, 2903-2908, 2014.

Yang, M., Yao, T., He, Y., and Thompson, L. G.: ENSO events recorded in the Guliya ice core, Climatic Change, 47, 401-409, 2000.

Yu, Y., Yang, T., Li, J., Liu, J., An, C., Liu, X., Fan, Z., Lu, Z., Li, Y., and Su, X.: Millennial-scale Holocene climate variability in the NW China drylands and links to the tropical Pacific and 30 the North Atlantic, Palaeogeogr. Palaeocl., 233, 149-162, 2006.

Yuan, L.: Xibei Zaihuang Shi, Gansu Renmin Chubanshe, Lanzhou, 1815 pp., 1994.

Zhang, D., Li, H. C., Ku, T. L., and Lu, L. H.: On linking climate to Chinese dynastic change: spatial and temporal variations of monsoonal rain, Chinese Sci. Bull., 55, 77-83, 2010.

\section{Long-term regional precipitation disparity in northwestern China}

H. F. Lee et al.

Title Page

Abstract

Conclusions

Tables Figures

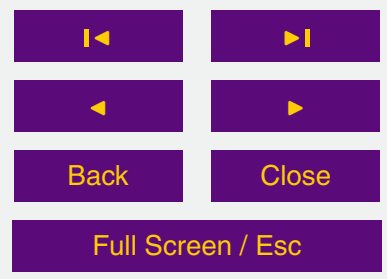

Printer-friendly Version

Interactive Discussion 
Zhang, P., Cheng, H., Edwards, R. L., Chen, F., Wang, Y., Yang, X., Liu, J., Tan, M., Wang, X., Liu, J., An, C., Dai, Z., Zhou, J., Zhang, D., Jia, J., Jin, L., and Johnson, K. R.: A test of climate, sun, and culture relationships from an 1810 year Chinese cave record, Science, 322, 940-942, 2008.

5 Zhang, Z., Cazelles, B., Tian, H., Stige, L. C., Bräuning, A., and Stenseth, N. C.: Periodic temperature-associated drought/flood drives locust plagues in China, P. Roy. Soc. B-Biol. Sci., 276, 823-831, 2009.

Zhao, S.: Physical Geography of China, Science Press, Beijing, China, 209 pp., 1986.
CPD

10, 3097-3125, 2014

\section{Long-term regional precipitation disparity in northwestern China}

H. F. Lee et al.

\section{Title Page}

Abstract Introduction

Conclusions References

Tables

Figures

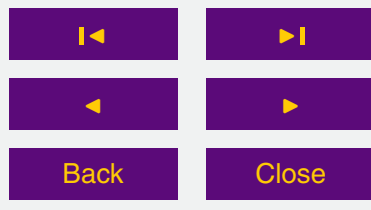

Full Screen / Esc

Printer-friendly Version

Interactive Discussion 


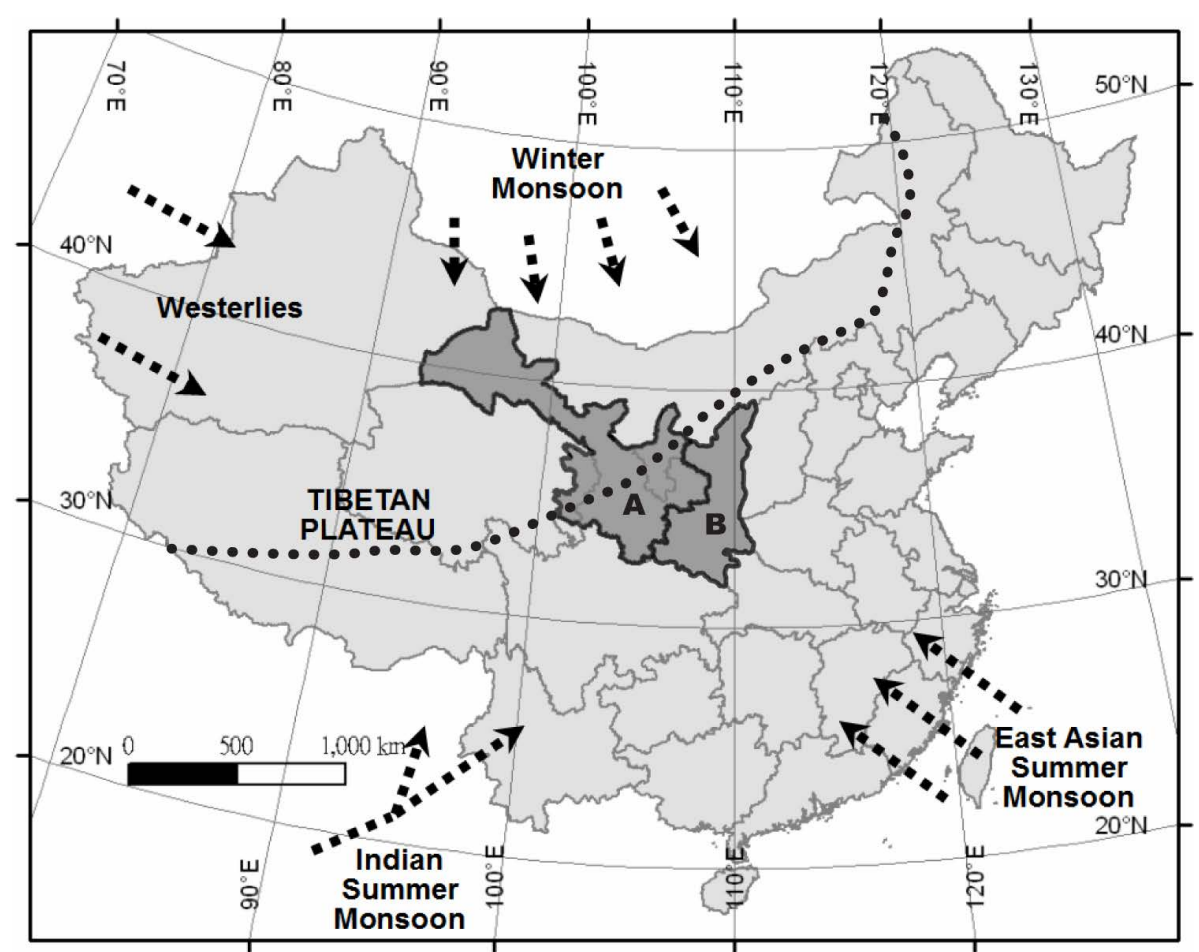

Figure 1. Map showing the location and the physical setting of our study area. Our study area includes two macro regions in NW China, namely (A) GNQR and (B) Sha'anxi, which are highlighted in gray. Arrows represent ASM (including East Asian Summer Monsoon and Indian Summer Monsoon), Westerlies, and Winter Monsoon. Dotted line illustrates the approximate present-day northern limit of ASM.

\section{CPD}

10, 3097-3125, 2014

\section{Long-term regional precipitation disparity in northwestern China}

H. F. Lee et al.

\section{Title Page}

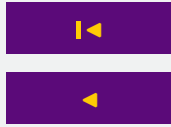

\section{$\rightarrow 1$}

Back $\triangleright$

\section{Full Screen / Esc}

Printer-friendly Version

Interactive Discussion 


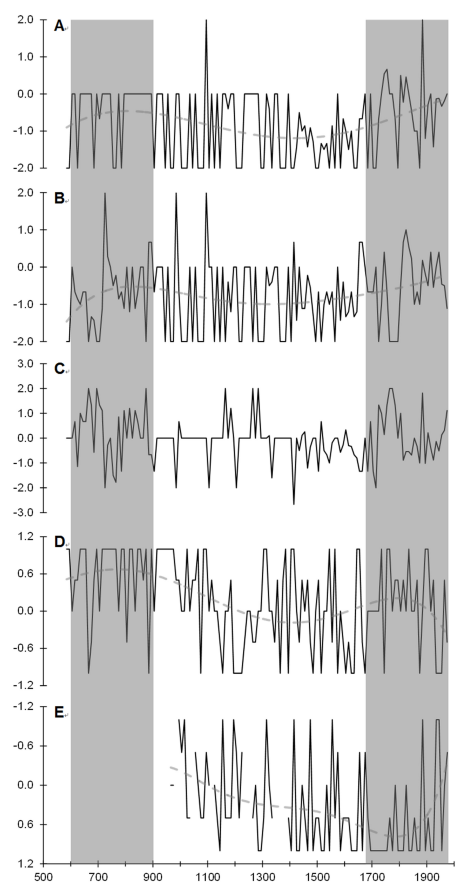

Figure 2. Precipitation/moisture reconstructions of NW China. In this study, we base on historical flood and drought records to reconstruct (A) $\mathrm{PI}_{\mathrm{GNQR}}$, (B) $\mathrm{PI}_{\text {Sha'anxi }}$, and (C) RPD. They are spanned AD580-1979 (see Sect. 2.1). We also include the precipitation/moisture reconstructions of (D) Hai River and Xi'an region (Yan et al., 1993) and (E) Longxi (Tan et al., 2008), which are also based on historical flood and drought records, for comparison. For (E), higher value means less precipitation. Its y-axis is inverted to facilitate comparison. Grey dashed lines represent the long-term trends (five-order polynomial fit) of the precipitation/moisture reconstructions; grey-shaded areas represent the periods with apparent regional precipitation disparity. All of the above indices are in decadal units.

\section{CPD}

10, 3097-3125, 2014

\section{Long-term regional precipitation disparity in northwestern China}

H. F. Lee et al.

\section{Title Page}

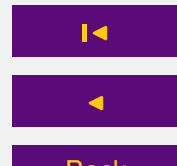

\section{$\rightarrow 1$}

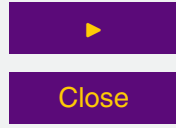

Full Screen / Esc

Printer-friendly Version

Interactive Discussion 
A

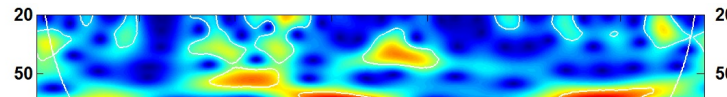

A 100

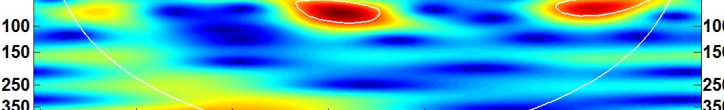

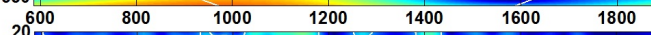

B
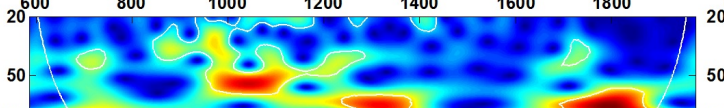

$100-\longrightarrow-\infty-100$

$150=$

350

$1000-1200$

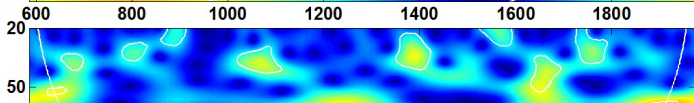

C
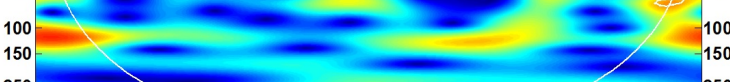

250

350

$600 \quad 800$$$
100
$$

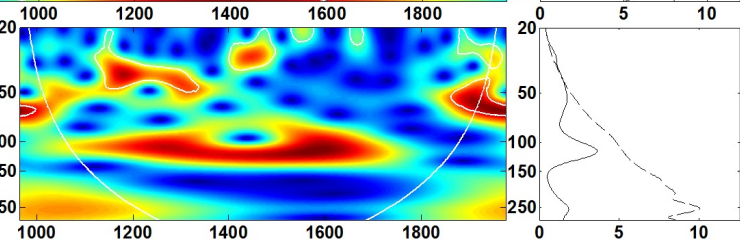

E
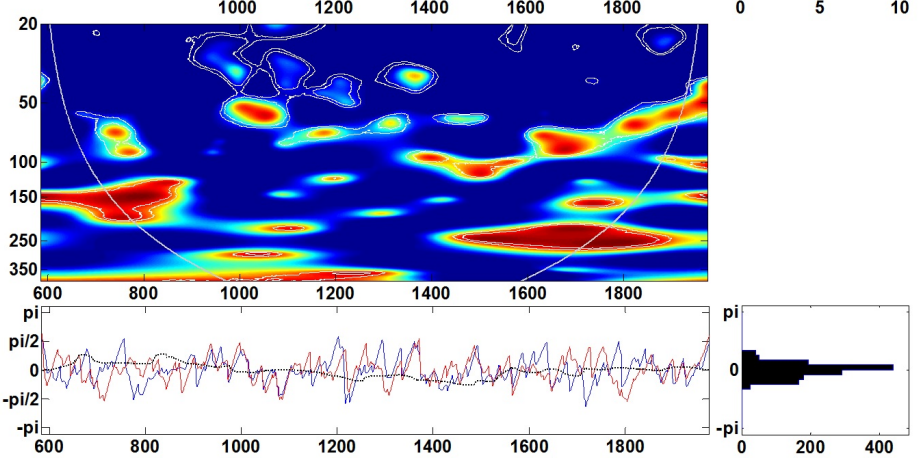

CPD

10, 3097-3125, 2014

\section{Long-term regional precipitation \\ disparity in northwestern China}

H. F. Lee et al.

\section{Title Page}

Abstract

Introduction

Conclusions

References

Tables

Figures

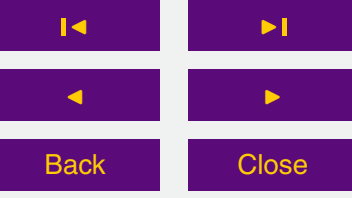

Full Screen / Esc

Printer-friendly Version

Interactive Discussion 
Figure 3. Wavelet analysis of various precipitation/moisture reconstructions of NW China: (A) $\mathrm{PI}_{\mathrm{GNQR}}$, (B) $\mathrm{Pl}_{\text {Sha'anxi }}$, (C) Hai River and Xi'an region (Yan et al., 1993), and (D) Longxi (Tan et al., 2008). For the left graphs of (A) to (D), continuous wavelet power spectra of the reconstructions are shown. The color code for power values varies from dark blue (low values) to dark red (high values) and the white curve indicates the cone of influence that delimits the region not influenced by edge effects. For the right graphs of (A) to (D), the average wavelet power spectra of the reconstructions are presented. The dashed lines show the $\alpha=5 \%$ significance levels computed based on 1000 Markov bootstrapped series. $P$ values associated with the values within the region delineated by the dashed line are less than $5 \%$. The wavelet coherency between $\mathrm{PI}_{\mathrm{GNQR}}$ and $\mathrm{PI}_{\text {Sha'anxi }}$ is shown in (E). For the upper-left graph of $(\mathrm{E})$, the color code for coherence values varies from dark blue (low values) to dark red (high values). The white curve indicates the cone of influence that delimits the region not influenced by edge effects and the dashed line show the $\alpha=10 \%$ significance levels computed based on 1000 Markov bootstrapped series. For the lower-left graph of $(E)$, the dotted lines represent phase difference; the red line represents the phase of $\mathrm{PI}_{\mathrm{GNQR}}$; and the blue lines represent the phase of $\mathrm{PI}_{\text {Sha'anxi }}$. For the lower-right graph of $(\mathrm{E})$, the distribution of the phase difference of $\mathrm{PI}_{\mathrm{GNQR}}$ and $\mathrm{PI}_{\text {Sha'anxi }}$ is shown.

\section{Long-term regional precipitation disparity in northwestern China}

H. F. Lee et al.

\section{Title Page}

Abstract Introduction

Conclusions References

Tables Figures

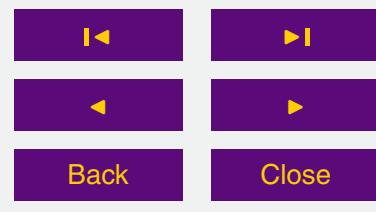

Full Screen / Esc

Printer-friendly Version

Interactive Discussion 


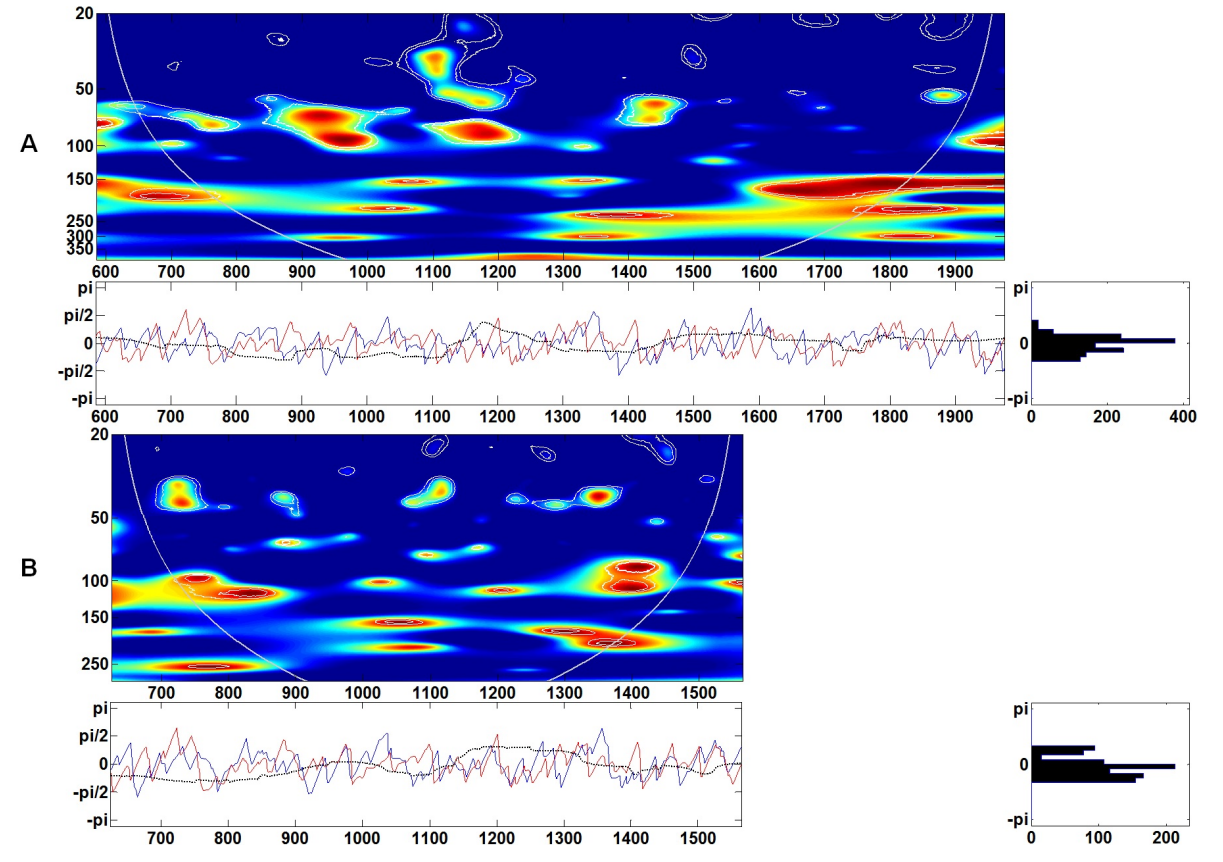

Figure 4. Wavelet coherency between RPD and ASM reconstructions by (A) Zhang et al. (2008) and (B) Berkelhammer et al. (2010), respectively. For the upper-left graphs of (A) and (B), the color code for coherence values varies from dark blue (low values) to dark red (high values). The white curve indicates the cone of influence that delimits the region not influenced by edge effects and the dashed line show the $\alpha=10 \%$ significance levels computed based on 1000 Markov bootstrapped series. For the lower-left graphs of (A) and (B), the dotted lines represent phase difference; the red line represents the phase of the atmospheric circulation considered; and the blue lines represent the phase of RPD. For the lower-right graph of (A) and (B), the distribution of the phase difference of the two considered time series is shown.

\section{CPD}

10, 3097-3125, 2014

\section{Long-term regional precipitation disparity in northwestern China}

H. F. Lee et al.

\section{Title Page}

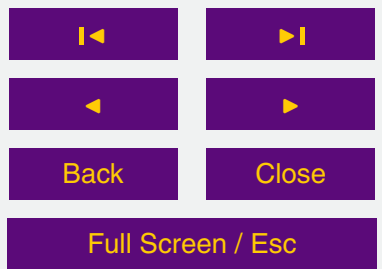

Printer-friendly Version

Interactive Discussion 


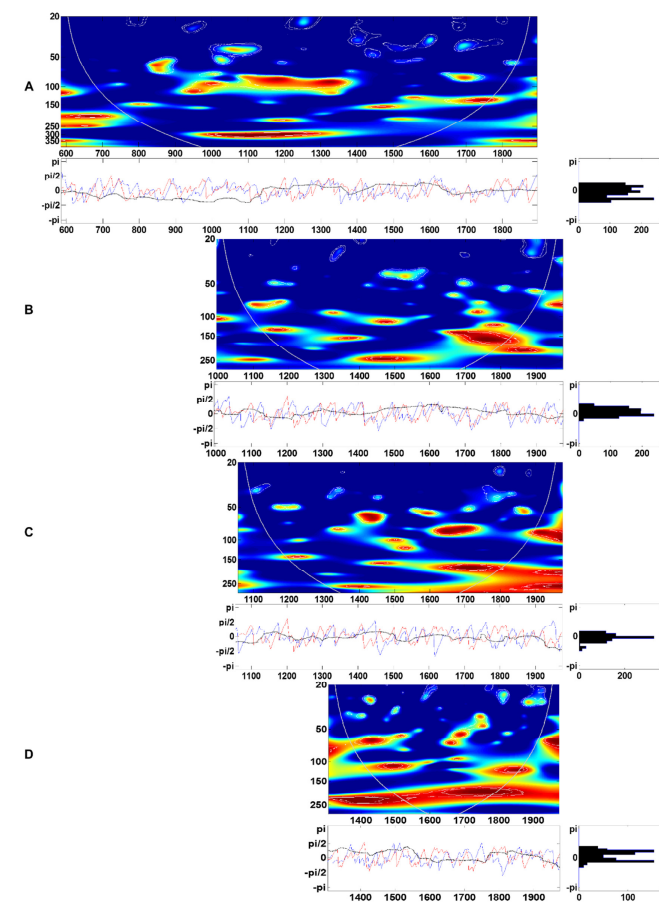

Figure 5. Wavelet coherency between RPD and (A) AO (Chu et al., 2008), (B) PDO (MacDonald and Case, 2005), (C) NAO (Trouet et al., 2009), and (D) ENSO (Li et al., 2013), respectively. For the upper-left graphs of (A) to (D), the color code for coherence values varies from dark blue (low values) to dark red (high values). The white curve indicates the cone of influence that delimits the region not influenced by edge effects and the dashed line show the $\alpha=10 \%$ significance levels computed based on 1000 Markov bootstrapped series. For the lower-left graphs of (A) to (D), the dotted lines represent phase difference; the red line represents the phase of the atmospheric circulation considered; and the blue lines represent the phase of RPD. For the lower-right graph of (A) to (D), the distribution of the phase difference of the two considered time series is shown.
CPD

10, 3097-3125, 2014

\section{Long-term regional precipitation disparity in northwestern China}

H. F. Lee et al.

\section{Title Page}

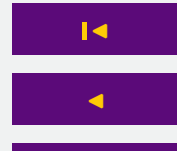

\section{$\rightarrow 1$}

Back

Close

\section{Full Screen / Esc}

Printer-friendly Version

Interactive Discussion 


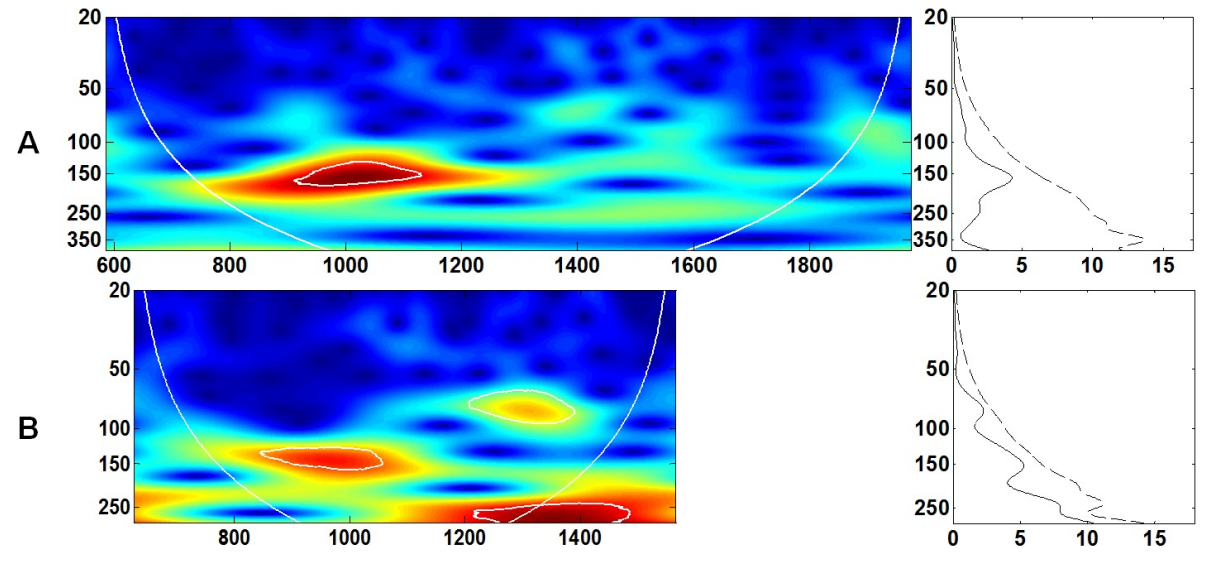

Figure A1. Continuous wavelet power spectra and the average wavelet power spectra of (A) Zhang et al.'s (2008) and (B) Berkelhammer et al.'s (2010) ASM reconstruction, respectively. For the left graphs of (A) and (B), continuous wavelet power spectra of the reconstructions are shown. The color code for power values varies from dark blue (low values) to dark red (high values) and the white curve indicates the cone of influence that delimits the region not influenced by edge effects. For the right graphs of (A) and (B), the average wavelet power spectra of the reconstructions are presented. The dashed lines show the $\alpha=5 \%$ significance levels computed based on 1000 Markov bootstrapped series. $P$ values associated with the values within the region delineated by the dashed line are less than $5 \%$.

\section{CPD}

10, 3097-3125, 2014

\section{Long-term regional precipitation disparity in northwestern China}

H. F. Lee et al.

\section{Title Page}

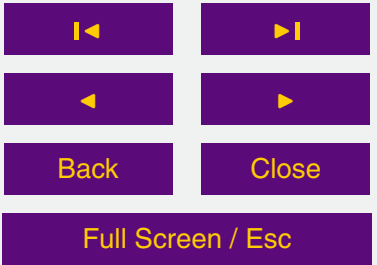

Printer-friendly Version

Interactive Discussion 